\title{
ENTREVISTA COM IGOR ANTÔNIO LOURENÇO DA SILVA
}

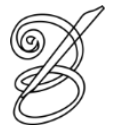 \\ Rodrigo D'Avila Braga SILVA ${ }^{1}$ \\ Mestrando em Estudos da Tradução (POSTRAD - CAPES) \\ Universidade de Brasília (UnB) \\ Brasília, Distrito Federal, Brasil \\ rodrigodavilabraga@gmail.com \\ Patrícia Rodrigues COSTA ${ }^{2}$ \\ Doutoranda em Estudos da Tradução (PGET - CAPES) \\ Universidade Federal de Santa Catarina (UFSC) \\ Florianópolis, Santa Catarina, Brasil \\ prcosta1986@gmail.com
}

gor Antônio Lourenço da $\operatorname{Silva}^{3}$ é professor adjunto da Universidade Federal de
Uberlândia (UFU). É doutor (2012) e mestre (2007) em Linguística Aplicada pela
Universidade Federal de Minas Gerais, onde também cursou o bacharelado e licenciatura em Letras - Inglês. Fez parte do seu doutorado na Universität des Saarlandes, Alemanha, com bolsa concedida pela CAPES. Atua principalmente nos seguintes temas: abordagem processual da tradução, abordagem discursiva da tradução, rastreamento ocular (eyetracking), Linguística de Corpus e Linguística Sistêmico-Funcional. Trabalhou na Universidade do Sarre (Alemanha) e foi professor visitante na Universidade de Macau.

Essa entrevista é fruto da palestra "O Rastreamento Ocular sob o Olhar da Tradução: Perspectivas de Pesquisa”, realizado na Universidade de Brasília em 27 de maio de 2014.

\section{O que é Rastreamento Ocular (RO)?}

LOURENÇO: Em termos simples, o rastreamento ocular (eye tracking) consiste em registrar e medir a atividade ou os movimentos dos olhos para a execução de uma atividade como contemplar uma paisagem, ler uma notícia de jornal ou buscar informações em uma página da internet. Por meio de RO, buscamos identificar o que de fato olhamos, o que ignoramos, a que estímulos a nossa pupila reage e, de forma indireta, em que concentramos a nossa atenção e como se dá o nosso processamento cognitivo ao realizarmos, por exemplo, uma tarefa de leitura ou tradução. 


\section{Como o RO é usado?}

LOURENÇO: O rastreamento ocular evoluiu bastante desde os primeiros mecanismos intrusivos desenvolvidos no final do século XIX. Hoje em dia, existem equipamentos mais adequados para fins de RO.

Basicamente, em pesquisas na psicolinguística e em estudos de leitura e tradução, usamos quatro tipos de equipamentos, os quais são escolhidos dependendo do grau de precisão que se deseja em relação aos dados e do quanto se deseja aproximar a pesquisa das condições reais de execução de uma tarefa. Em geral, quanto mais preciso o equipamento, mais artificiais são as condições em que se coletam os dados. O equipamento de eye tracking mais preciso é aquele em que a pessoa não pode movimentar a cabeça, devendo apoiar o queixo em um descanso (head supported eye tracker); depois vem um em que o aparelho é "montado" na cabeça da pessoa, o que permite um pouco de movimento (head mounted eye tracker); em seguida, vem aquele em que a pessoa simplesmente se posiciona na frente de um monitor e tem relativa liberdade para movimentar a cabeça (remote eye tracker); e por último

142 vem aquele embutido em óculos que dispensam que a pessoa olhe necessariamente para um monitor como no caso dos demais equipamentos (glass eye tracker).

$\mathrm{Na}$ maior parte dos equipamentos modernos, emite-se uma luz infravermelha ou de infravermelho próximo e o sistema busca um dos olhos ou ambos com base no reflexo dessa luz na pupila. Considerando o centro da pupila e a reflexão da luz, alguns algoritmos projetam o ponto em que a pessoa está olhando para o vídeo em determinado momento. Vale destacar que é preciso fazer uma calibragem do equipamento para cada pessoa antes de começar a coleta de dados e sublinhar que a luz emitida encontra-se dentro de padrões internacionais para que não sejam causados danos aos olhos dos participantes.

\section{Como o Rastreamento Ocular contribui para pesquisa em Tradução?}

LOURENÇO: O uso do RO nos estudos processuais da tradução parte da premissa de que os movimentos oculares são indicativos de processamento cognitivo. Em outras palavras, entende-se que não haja intervalo - ou que ele seja ínfimo - entre o que se está olhando em dado momento e o que se está processando cognitivamente. Assumindo essa premissa como verdadeira, ao utilizarmos o RO nos estudos da tradução, podemos presumir o que o tradutor está processando com base nas palavras em que ele está fixando, ou seja, em que ponto do 
texto ele está concentrando o olhar por determinado período de tempo ou por determinado número de vezes.

Mais especificamente, podemos identificar em que momento da realização de uma tarefa o tradutor se depara com um problema de tradução ou envida esforço para chegar a uma solução. Para tal, baseamo-nos em duas métricas: fixações e sacadas. As fixações são pontos relativamente fixos em que se está focando o olhar em determinado momento (geralmente de 180 a 400 milissegundos), e as sacadas são os intervalos entre uma fixação e outra. Quanto mais vezes ou quanto mais tempo um tradutor fixa o olhar em determinada parte do texto e quanto mais vezes as sacadas indicam movimentos de retrocesso na leitura do texto, maior é o esforço cognitivo envidado para processar essa parte do texto.

Essa abordagem, que, nos estudos da tradução, vem sendo utilizada com mais vigor nos últimos cinco anos, abriu novas perspectivas de pesquisa e novos caminhos para entendimento do processo tradutório. Até então, contávamos com verbalizações dos tradutores durante ou após a execução de uma tarefa tradutória e com softwares que registravam os movimentos de teclado e de mouse, bem como as pausas entre eles, durante a execução de uma tarefa. Essas técnicas de coleta de dados, apesar de suas vantagens e das grandes contribuições que trouxeram e ainda trazem para os estudos processuais da tradução, não nos permitem compreender como o tradutor se orienta para realizar a tarefa, o que lê - e como lê - do texto de partida nem o que revisa - e como revisa - do texto de chegada. Quando falávamos de unidades de tradução, por exemplo, olhávamos o segmento de texto produzido pelo tradutor entre duas pausas de 2,4 segundos ou mais para supor o que ele estava processando do texto de partida. No entanto, por definição, unidade de tradução é a porção do texto de partida na qual o tradutor foca a sua atenção e, portanto, para realmente termos um acesso mais realista a ela, precisamos de acesso a dados de leitura como aqueles que o RO hoje nos fornece.

\section{Em que campo dos Estudos da Tradução podemos situar a pesquisa com Rastreamento} Ocular? Quais as aplicações do RO para a área de tradução como um todo?

LOURENÇO: O RO está sendo utilizado no âmbito dos estudos processuais da tradução. As pesquisas atualmente se voltam para os seguintes aspectos:

a) diferença entre ler para fins de interpretação (compreensão) de texto e ler para fins de tradução; 
b) descrição do perfil do tradutor novato, do tradutor profissional, do tradutor experiente etc.;

c) identificação e resolução de problemas de tradução;

d) esforço cognitivo nas fases de orientação (leitura anterior à digitação do primeiro caractere), redação e revisão da tradução;

e) diferença entre processamento do texto de partida e processamento do texto de chegada, compreendendo as transições entre um e outro; e

f) diferença entre tradução humana e pós-edição de textos resultantes de tradução automática.

Algumas variáveis independentes podem ser adicionadas a esses estudos, como os pares linguísticos, a direcionalidade (da língua materna ou para ela) e a qualidade da tradução automática.

5. Qual(is) universidade(s) em que a pesquisa com RO é mais desenvolvida no mundo? E no Brasil?

LOURENÇO: Em se tratando dos estudos da tradução, o RO está sendo utilizado com mais ímpeto na Dublin City University (Irlanda), na Copenhagen Business School e na University of Copenhagen (Dinamarca), na Universidade de Macau (China), na Johannes GutenbergUniversität (Alemanha), na Universidade Federal de Minas Gerais e na Universidade Federal de Ouro Preto (Brasil).

6. Qual a aplicação do rastreamento ocular na sala de aula de prática de tradução?

LOURENÇO: Provavelmente por se tratar de um equipamento caro (tanto o hardware quanto o software), não se ouvem relatos de uso direto do RO na sala de aula. No entanto, dados coletados em pesquisas podem ser utilizados para fins didáticos. Por exemplo, é possível selecionar excertos de vídeo de uma tarefa tradutória coletada com RO e mostrar para os alunos como um tradutor processou um problema de tradução e chegou a determinada solução. Pode-se inicialmente pedir aos alunos que traduzam os textos em sala de aula ou em casa e, em seguida, mostrar como o texto foi traduzido por um profissional e/ou por um novato. Os vídeos com "bolinhas" indicando as fixações chamam bastante atenção dos alunos e são bem esclarecedores quando se quer mostrar ou comparar o que tradutores profissionais e 
os tradutores novatos fazem. Atividades desse tipo podem aumentar a capacidade de reflexão dos alunos sobre o ato tradutório e sobre a multiplicidade de soluções que é possível encontrar para um mesmo problema.

\section{Quais são os resultados concretos/práticos desse tipo de pesquisa?}

LOURENÇO: Em primeiro lugar, tem-se a perspectiva de formação dos tradutores. Entender o que tradutores profissionais ou expertos (experts) fazem e como se diferenciam de tradutores novatos é um passo importante para podermos projetar atividades que otimizem o desenvolvimento da competência tradutória. Além disso, atividades como a descrita acima (Questão 6) também são importantes para o desenvolvimento da metarreflexão, ou seja, a habilidade ou capacidade de monitorar ou gerenciar o próprio processo de tradução e refletir sobre ele a posteriori.

Em segundo lugar, tem-se a perspectiva da interação homem-máquina. Com o desenvolvimento dos tradutores automáticos, é inegável que a pós-edição cada vez mais fará parte da prática profissional de muitos tradutores. Entender como a pós-edição é feita por profissionais é um passo importante para projetar atividades que otimizem o desenvolvimento de competências nessa área e também para entender como - e se ou sob que condições - de fato pós-editar poupa esforços em termos de cognição, tempo e digitação. Com isso, pode-se apresentar argumentos mais bem informados para se aceitar ou não a pós-edição na prática profissional, uma vez que ela também tem impacto nos preços praticados no mercado.

Em terceiro lugar, tem-se a possibilidade de desenvolvimento de aplicações inteligentes para o tradutor. Por exemplo, conhecendo melhor como o tradutor transita entre o texto de partida, o texto de chegada e outros elementos da interface de um programa, que podem estar em diferentes posições da tela, é possível melhorar os sistemas de memória de tradução e/ou de pós-edição, dispondo-os, ou permitindo que sejam dispostos, em locais mais confortáveis. Outro exemplo: conhecendo o tempo mínimo de fixação ou o número mínimo de fixações em determinado ponto do texto, é possível projetar aplicações que abram um dicionário ou uma página na internet contendo informações sobre aquela palavra ou expressão em que o tradutor está fixando mais vezes ou por mais tempo. 


\section{Quais as limitações/dificuldades do equipamento e da pesquisa?}

LOURENÇO: A maior dificuldade em relação ao RO está nos preços praticados pelas principais empresas no mercado, que cobram não só pelo hardware (eye tracker), mas também pela licença do software que é capaz de compilar e/ou interpretar os dados coletados pelo equipamento. Existem programas gratuitos utilizados especificamente para os estudos da Tradução, como é o caso do Translog-II, desenvolvido na Copenhagen Business School, mas, mesmo assim, o custo do hardware é substancial.

Vencida a barreira financeira, existem as limitações técnicas do uso do RO. É preciso fazer coleta em um ambiente iluminado por luz artificial, pois a intensidade da luz pode afetar a confiabilidade dos dados. É ideal que os participantes não usem óculos ou lentes de contato e tampouco maquiagem, porque podem alterar a qualidade dos dados. Não convém que sejam utilizadas fontes externas de consulta, porque os programas de RO associam a fixação a uma coordenada na tela do computador; portanto, um ponto (x,y) na tela será sempre interpretado como a mesma coisa, independentemente se o tradutor estiver visualizando o Word ou o

146 Internet Explorer. É necessário utilizar textos pequenos, pois, além de se ter de evitar o uso da barra de rolamento, sabe-se que utilizar espaçamento e fontes maiores amplia a qualidade dos dados e sabe-se que, mesmo um texto pequeno, gera um volume muito grande de dados para ser processado e analisado pelo pesquisador. Embora análises quantitativas sejam relativamente de fácil operacionalização, análises qualitativas muitas vezes são necessárias e mais elucidativas e, com um grande volume de dados (horas de gravação), análises dessa natureza são inviabilizadas ou tomam muito tempo. Além disso, mesmo com todos os cuidados, é possível que haja perda de dados, porque o participante pode se movimentar demais ou pode haver qualquer incidente de ordem técnica durante as coletas de dados.

Também há limitações específicas das pesquisas dos estudos processuais da tradução. Uma delas é selecionar textos que permitam a realização de tarefas comparáveis. Em alguns casos, o que se tem feito é manipular os textos para que haja diferenças apenas em pontos específicos. Outra dificuldade é encontrar um número significativo de sujeitos que permita realizar testes estatísticos, dificuldade essa ampliada pelo fato de que, em muitos casos, existe uma escassez de tradutores com perfis similares em determinados contextos.

Cabe ainda lembrar que o equipamento adquirido também influencia bastante o tipo de dado que pode ser coletado e, consequentemente, o tipo de pesquisa que se pode realizar. Por exemplo, pesquisas interessadas no tempo de reação, ou seja, quantos milésimos de segundo 
se passa entre um evento e a reação a ele, precisam de equipamentos mais precisos e, portanto, não podem ser conduzidas com eye trackers que permitem movimentos relativamente bruscos da cabeça. Pesquisas desse tipo são comuns na psicolinguística, mas não nos estudos da tradução.

\section{Há alguma dificuldade específica no treinamento e no processo de coleta de dados?}

LOURENÇO: Como se trata de hardware e software bastante específicos, é necessário que o pesquisador seja treinado em como manusear o equipamento e o programa e como preparar as coletas, realizar o experimento e, depois, manipular e interpretar os dados coletados. Em geral, até mesmo pelo interesse em ampliar os estudos na área, o que se tem observado é uma troca de experiência entre os pesquisadores, o que facilita o aprendizado e evita a repetição de erros.

Em se tratando dos participantes das coletas, não há necessidade de treinamento. Uma breve explicação sobre a pesquisa e sobre o equipamento em geral basta para a realização da pesquisa. O que mais toma tempo geralmente é o momento da calibragem, uma vez que, dependendo da pessoa, é preciso reproduzir o procedimento diversas vezes para que o equipamento identifique corretamente o olhar do participante.

Cabe também destacar a necessidade de aprovação da pesquisa pelo Comitê de Ética e assinatura do Termo de Consentimento Livre e Esclarecido pelo participante. Não se trata exatamente de uma dificuldade, mas de um aspecto imprescindível a que os pesquisadores da área devem atentar e que, naturalmente, toma certo tempo até que se obtenha parecer favorável e se possa de fato realizar a pesquisa.

\section{Pode-se traçar um perfil do tradutor pelo RO?}

LOURENÇO: Um dos objetivos das pesquisas com RO é traçar os diferentes perfis de tradutores: novatos, experientes, expertos, profissionais etc. Como se trata de pesquisas recentes que envolvem diversas variáveis, como pares linguísticos, tipos de texto e direção da tradução, ainda não há dados concretos sobre cada um desses perfis. Um dos resultados nesse sentido que se pode apontar no momento é que parece haver dois tipos de processamento para a realização de traduções: em paralelo ou em série. O processamento paralelo seria quando o tradutor lê, por vez, pequenos segmentos (geralmente no nível da palavra ou do sintagma) do 
texto de partida e os traduz imediatamente. O processamento em série é quando o tradutor lê porções substanciais do texto de partida (toda uma sentença, por exemplo) para depois produzir, em porções menores, o texto de chegada, o que pode incluir retomar a leitura de porções menores do texto de partida.

11. Qual seria a importância do RO para o ensino de tradução? Pode ser considerado uma metodologia de ensino ou uma ferramenta de auxílio aos professores? É possível perceber a efetividade da abordagem de ensino escolhida por meio do uso do RO?

LOURENÇO: Como apontado nas Questões 6 e 7, as pesquisas processuais em tradução - e em especial aquelas usando o RO - têm grande importância para o ensino da tradução no sentido de que, conhecendo o processo de tradutores profissionais e de tradutores expertos, é possível projetar atividades mais bem informadas que otimizem o desenvolvimento da competência tradutória. Partindo do pressuposto de que essa competência se desenvolve mediante conhecimentos declarativos (saber o quê) e conhecimentos procedimentais (saber 148 como), é importante desenhar atividades e currículos que tenham embasamento teórico e empírico no que diz respeito ao que realmente se deve saber em termos procedimentais e declarativos para se formar como um tradutor competente. Muitas vezes, o professor de tradução recorre à sua própria experiência ou intuição para elaborar atividades e unidades didáticas, e um embasamento teórico e empírico pode muito contribuir para um melhor desenvolvimento dessas atividades ou mesmo elaboração de atividades novas e inovadoras.

Em minha experiência em sala de aula, o uso do RO e de outras técnicas utilizadas em pesquisas processuais da tradução, como relatos retrospectivos (falar sobre a tradução após realizá-la) ou key logging (registro dos movimentos de teclado e mouse), parece ser efetivo no ensino, tanto para o desenvolvimento da competência tradutória quanto para o despertar de interesse para pesquisas em tradução. Os alunos se surpreendem, por exemplo, quando se aponta - com dados irrefutáveis! - que boa parte dos problemas de tradução do seu próprio texto se deve à falta de leitura de todo o texto de partida (em geral pequeno) antes de iniciar a tarefa. Nesse caso, com a gravação em tempo real do que fazem, fica nítido que, em dez segundos, não houve tempo suficiente para ler um texto de, por exemplo, 200 palavras. Muitas vezes, essa leitura inicial (chamada de fase de orientação) parece ser um grande diferencial no desempenho do tradutor. 
LOURENÇO: A Universidade Federal de Minas Gerais (UFMG), sob a coordenação do Prof. Dr. Fabio Alves e da Profa. Dra. Adriana Pagano, foi pioneira no uso do RO para fins de pesquisa em tradução no Brasil. Os trabalhos começaram com investigações sobre diferenças entre ler para compreender um texto, ler para traduzir o mesmo texto e ler para fazer uma tradução à prima vista (sight translation) desse texto. Em seguida, no âmbito de um projeto internacional desenvolvido com a Universidade do Sarre (Alemanha), foi realizada uma pesquisa voltada para a investigação de como tradutores profissionais e pesquisadores da física lidavam com diferentes níveis de implicitudude/explicitude em duas versões de um mesmo texto de partida em inglês (de popularização da ciência) que deveria ser traduzido para o alemão ou para o português. Atualmente, as pesquisas estão mais direcionadas para a interação homem-máquina, com estudos investigando a diferença no esforço cognitivo, temporal e técnico despendido pelos participantes ao traduzirem do zero e ao pós-editarem e/ou editarem um texto que passou por um tradutor automático. Grosso modo, a pós-edição acontece quando se revisa/corrige o texto de chegada tendo acesso ao texto de partida, enquanto a edição ocorre quando se revisa/corrige o texto de chegada sem qualquer acesso ao texto de partida.

Tive a oportunidade de participar das pesquisas desenvolvidas na UFMG desde o seu início, em 2009, então como doutorando. Hoje, como professor da Universidade Federal de Uberlândia (UFU), participo como pesquisador associado ao Laboratório Experimental de Tradução (LETRA), da Faculdade de Letras da UFMG. Na colaboração que desenvolvemos entre a UFMG e a UFU, temos realizado pesquisas voltadas para a interação homem-máquina e estendido as frentes de trabalho para pesquisas em conjunto com a Universidade Federal de Ouro Preto, a Dublin City University, a Copenhagen Business School e a Universidade de Macau. Além disso, com o interesse dos professores Gleiton Malta Magalhães e Kyoko Sekino, da Universidade de Brasília (UnB), temos expandido ainda mais a rede de colaboração voltada para a investigação da tradução mediante o uso de rastreamento ocular.

Ultimamente, na UFU, um dos principais trabalhos no momento é a automatização do processamento dos dados gerados em arquivos XML pelo Translog-II. Um bolsista do curso de Sistemas da Informação, Gabriel Eduardo da Silva, está concluindo uma aplicação para que os dados sejam transformados em planilhas que possam ser lidas pelo MS Excel ou por programas mais sofisticados como o R ou o SPSS. Uma aplicação, já concluída, permite que 
os dados sejam apresentados como uma representação linear dos movimentos de teclado e das pausas entre esses movimentos. Essas aplicações são de código aberto e podem ser obtidas gratuitamente nos seguintes endereços: <https://github.com/gabrieleduardo/MicroUnits> e $<$ https://github.com/gabrieleduardo/LRSB> .

${ }^{1}$ Lattes Rodrigo D’Avila Braga Silva. Disponível em: http://lattes.cnpq.br/1746993519090773

${ }^{2}$ Lattes Patrícia Rodrigues Costa. Disponível em: http://lattes.cnpq.br/9546437584230118

3 Lattes Igor Antônio Lourenço da Silva. Disponível em: http://lattes.cnpq.br/6440150670404908 E-mail: ialsigor@gmail.com

RECEBIDO EM: 26 de novembro de 2015 ACEITO EM: 07 de dezembro de 2015 